\title{
Change in Anterior Crowding over 20 Years from Third Decade of Life in Untreated Angle Class I Crowding
}

\author{
Yuka Saito $^{1)}$, Aiko Tanoi ${ }^{1)}$, Etsuko Motegi ${ }^{{ }^{2}}$ and Kenji Sueishi ${ }^{2)}$ \\ ${ }^{1)}$ Department of Orthodontics, Tokyo Dental College, \\ 1-2-2 Masago, Mihama-ku, Chiba 261-8502, Japan \\ 2) Department of Orthodontics, Tokyo Dental College, \\ 2-9-18 Kanda-Misakicho, Chiyoda-ku, Tokyo 101-0061, Japan
}

Received 24 July, 2018/Accepted for Publication 26 December, 2018 Published Online in J-STAGE 31 July, 2019

\begin{abstract}
Many studies have investigated age-related change in normal occlusion and during the post-retention phase of orthodontic treatment. None, however, have investigated such change in malocclusion. The purpose of this study was to compare age-related change in Angle Class I crowding with that in normal occlusion. Dental casts obtained from 10 men and 2 women in their 20s and then again in their 40s were digitized with a 3-dimensional laser scanner to measure anterior crowding, angulation, inclination, and arch width and length. A paired $t$-test was used to evaluate change in these values between the two sets of casts. A student's $t$-test was used to compare values between the crowding and normal groups. The casts obtained from individuals with untreated Angle Class I crowding revealed that anterior crowding increased with age due to a decrease in the length of the maxillary arch. Clear lingual inclination of the maxillary incisors and mesiolingual inclination of the maxillary canines were also observed. A decrease was observed in the anterior arch width and an increase in crowding due to lingual inclination of the mandibular canines in the mandible. The space between the mandibular central incisors and between the mandibular lateral incisors and canines was particularly associated with an increase in crowding, suggesting that this was age-related. A comparison between patients in their 40s with Angle Class I crowding and those with normal occlusion revealed that the increase in maxillary anterior crowding was greater in the former. Mandibular anterior crowding increased at around the same rate, however.
\end{abstract}

Key words: Age-related change — Untreated Angle Class I crowding -

20s and 40s-Anterior crowding - Three-dimensional laser scanner

This paper was originally a thesis submitted to the Graduate School of Tokyo Dental College in March 2014 by Yuka Saito. 


\section{Introduction}

The ultimate goal of orthodontic treatment is to improve irregularities in dentition and the occlusal relationship, and to attain the ideal normal occlusion for each person ${ }^{1,21,22)}$. To achieve this goal in patients at different stages of life, it is important to understand how the various parts of the oral cavity change with time.

Occlusion has been reported to differ depending on how various functions are performed due to long-term age-related change in the dentition in patients with normal occlusion who have not undergone orthodontic treatment $t^{4,5,10,15,23,26,28)}$. One study investigating maturation of untreated normal occlusion in individuals between the ages of 10 and 29 years revealed a decrease in mandibular arch length and inter-canine width, minimal overall change in intermolar width, and an increase in incisor irregularity ${ }^{23)}$. Another study investigating longitudinal change between the ages of 20 and 39 years in patients with normal untreated occlusion revealed an increase in maxillary and mandibular arch width, a decrease in occlusal vertical dimension, an increase in overjet and overbite, an increase in labial inclination, and an increase in mandibular anterior crowding ${ }^{15}$. One study investigated change in the dental arches in patients who had not undergone treatment between late adolescence and the fifth or sixth decade of life in comparison with in those who had undergone orthodontic treatment as adolescents at approximately 30 years post-treatment. The results revealed a decrease in maxillary and mandibular arch length and width, and an increase in mandibular anterior crowding; they also revealed significantly greater mandibular incisor irregularity in men than in women. No statistically significant correlations were observed between the various changes in dental arch values obtained, however ${ }^{4}$. Long-term stability in the dental arch form in patients with normal occlusion between the ages of 13 and 31 years has been reported. The results demonstrated large individual variation in age- related change in arch form. A significant change to a more rounded arch form with age was observed in the mandible, which was accompanied by a significant increase in inter-molar distance and a reduction in arch depth in men. A significant correlation was also observed between change in mandibular arch form and increased irregularity of the mandibular incisors. Further casts obtained from one individual in the patient cohort revealed slight dentoalveolar overgrowth in the mandible, and that anterior inclination had increased with age in the maxilla ${ }^{10)}$. Change in the longitudinal dental arch after adolescence through the sixth decade of life has been reported. That study revealed that dental arches continued to change and adapt throughout adulthood and into the sixth decade of life. These changes in arch width, depth, and length were decremental, and they reflected a continuation of trends documented in the years prior to the sixth decade, although the degree of change decreased with time. There was a tendency toward a more rounded arch form with age. This change in arch form resulted from a significant decrease in the depth of the maxillary and mandibular $\operatorname{arch}^{5)}$. Meanwhile, another study comprising a 40-year follow-up of dental arch dimension and incisor irregularity in adults confirmed that dentoalveolar processes continue to undergo physiological change throughout adult life. That study included a number of findings of potential clinical importance, including a decrease in arch length and depth, resulting in a decrease in inter-canine width and an increase in anterior crowding $^{28)}$. In clinical orthodontic practice, these findings have important implications for treatment planning and long-term stability after orthodontic treatment.

There are also many reports on long-term stability after orthodontic treatment ${ }^{3,6,11,17)}$, and one of the features of such studies is that they have demonstrated an increase in mandibular anterior crowding.

Thus, the literature contains many studies on age-related change in patients with normal occlusion who have not undergone orth- 
odontic treatment and in those during the post-retention phase of orthodontic treatment. To the best of our knowledge, however, no studies to date have investigated such change in malocclusion, and none have reported comparisons with normal occlusion. Knowledge of change in, and the characteristics of malocclusion, and information on the sites where crowding is most likely to occur are important if the goals of orthodontic treatment and to be achieved. Focusing on the high proportion of crowding among the various types of malocclusion observed in the Japanese population $^{30)}$, the purpose of the present study was to identify factors involved in age-related change in Angle Class I crowding.

\section{Materials and Methods}

This study was approved by the Ethics Committee of Tokyo Dental College (Approval Number: 281).

\section{Materials}

Dental plaster casts obtained from 203 students who graduated from Tokyo Dental College in 1990 or 1991 were examined, and 56 casts that satisfied the following conditions were selected:

1) Angle Class I crowding

2) Arch length discrepancy of $-4 \mathrm{~mm}$ or less

3) No history of orthodontic treatment

4) No missing teeth other than third molars

5) Restorative procedures limited to those for pit and fissure caries, and no prosthetic crown covering the cusps

6) No asymmetry in dental arch shape

7) Healthy periodontal tissue with no gingival recession or other abnormalities

Next, to investigate age-related change in the same individuals after 20 years, current dental plaster casts were requested from the providers of the original casts. A total of 22 such casts were subsequently submitted, among which 12 obtained from 10 men and 2 women with no history of orthodontic treatment and no prosthetic crowns covering the tooth cusp were selected. The dental casts from approximately 20 years earlier comprised the 20s group (mean age, 22 years) and the current dental casts were taken as the 40 s group (mean age, 42 years). To standardize the plaster dental casts, they were prepared with the occlusal plane horizontal and parallel to the basal plane.

Tanoi et $a{ }^{26}{ }^{26}$ reported age-related change in normal occlusion in people selected from the same population as that used in the present study. The materials and results of this earlier study, obtained from 8 men and 2 women, were used as the control group in the present study. The measurement method was essentially the same. A comparison was then made between Angle Class I crowding (Crowding group) and normal occlusion (Normal group). Maxillary and mandibular anterior crowding were measured again in the Normal group.

\section{Measurement method}

The 3-dimensional (3-D) shape of the parallel dental casts was inputted using a noncontact shape measuring system (VMS-100F, UNISN, Osaka, Japan). It was measured using a 3-D point processing software package (Imageware 13, Siemens PLM Software, Inc., Plano, TX, USA) ${ }^{7,8,19,26)}$.

The occlusal plane was established with the maxillary and mandibular teeth in occlusion using the following 3 reference points: an anterior reference point located at the center of the maxillary and mandibular central incisors where they overlap; and two more posterior reference points located bilaterally at the center of the maxillary and mandibular first molars, where they overlap. The following measurements were compared in the 3-D dental cast images in the same individuals in their 20s and 40s. Measurements were performed twice, and the mean of the left and right values was taken as the measurement value.

\section{Measurements}

1) Crowding (Figs. 1, 2)

With reference to the irregularity index of 


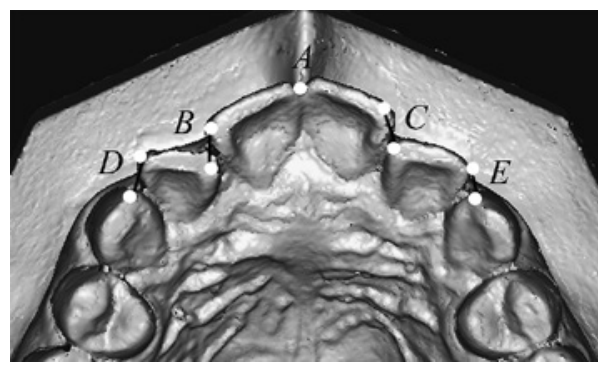

Fig. 1 Measurement method for crowding in maxilla Distance between contact points to canine mesial proximal surface

UT (sum of amount of maxillary crowding) $=\mathrm{A}+\mathrm{B}+\mathrm{C}+\mathrm{D}+\mathrm{E}$

U11 (amount of crowding between maxillary right and left central incisors) $=\mathrm{A}$

U12 (amount of crowding between maxillary central and lateral incisors $)=\mathrm{B}+\mathrm{C} / 2$ (average on left and right sides)

U23 (amount of crowding between maxillary lateral incisors and canines) $=\mathrm{D}+\mathrm{E} / 2$ (average on left and right sides)

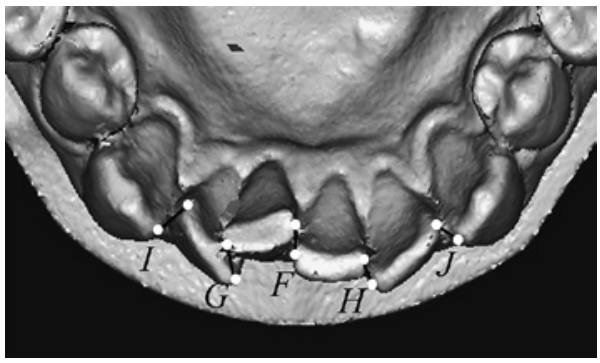

Fig. 2 Measurement method for crowding in mandible

Distance between contact points to canine mesial proximal surface

LT (sum of amount of mandibular crowding) $=\mathrm{F}+\mathrm{G}+\mathrm{H}+\mathrm{I}+\mathrm{J}$

L11 (amount of crowding between mandibular right and left central incisors) $=\mathrm{F}$

L12 (amount of crowding between mandibular central and lateral incisors) $=\mathrm{G}+\mathrm{H} / 2$ (average on left and right sides)

L23 (amount of crowding between mandibular lateral incisors and canines) $=\mathrm{I}+\mathrm{J} / 2$ (average on left and right sides)

Little $^{13)}$, distances between the crown contact points on adjacent teeth from the mandibular right to left canine were projected onto the occlusal plane and measured, and crowding was obtained as the sum of the distances between 5 contact points. These measure-

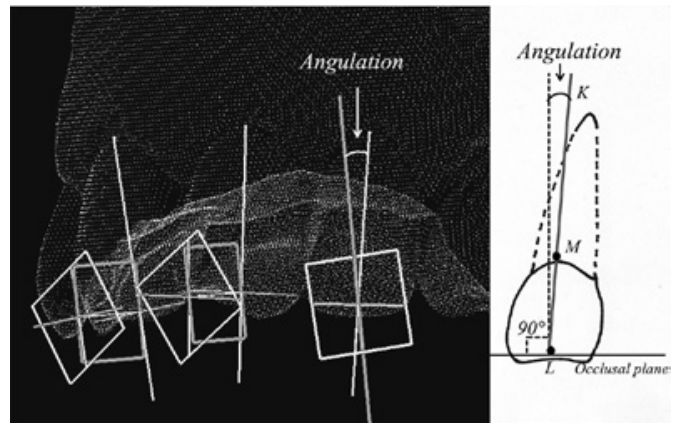

Fig. 3 Measurement of angulation

$\mathrm{K}$ line: tooth crown axis

L point: center of incisal edge

$\mathrm{M}$ point: deepest point of tooth cervical curve

ments are described below. The sum of the amount of mandibular crowding is referred to as LT; the amount of crowding between the mandibular right and left central incisors as L11; the amount of crowding between the mandibular central and lateral incisors as L12; and the amount of crowding between the mandibular lateral incisors and canines as L23. The same measurements were also performed in the maxilla, where the sum of maxillary crowding was referred to as UT; crowding between the maxillary right and left central incisors as U11; crowding between the maxillary central and lateral incisors as U12; and crowding between maxillary lateral incisors and canines as U23.

2) Angulation (Fig. 3)

The angle formed by the tooth crown axis and a line orthogonal to the occlusal plane was calculated ${ }^{8}$. Mesial inclination of the crown with respect to the occlusal plane is indicated as positive $(+)$ and distal inclination as negative $(-)$.

3) Inclination (Fig. 4)

The angle formed by a tangential line on the LA point (labial clinical crown midpoint) and a line orthogonal to the occlusal plane was calculated ${ }^{7}$. Labial inclination of the crown with respect to the occlusal plane is indicated as positive $(+)$ and lingual inclination as negative $(-)$.

4) Dental arch width and length ${ }^{19)}$ (Fig. 5)

Anterior width: distance between distal 


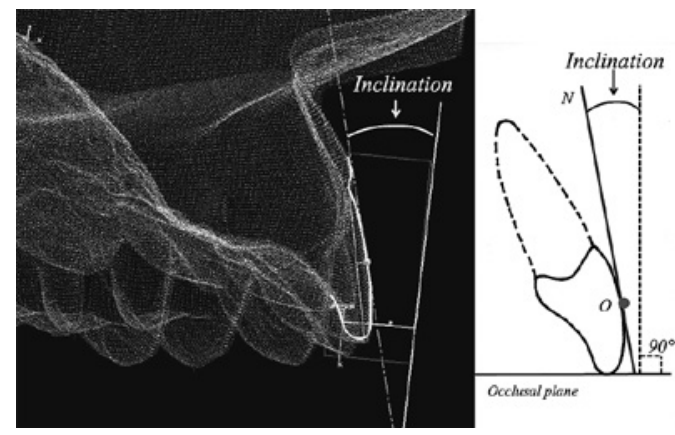

Fig. 4 Measurement of inclination

$\mathrm{N}$ line: tangential line on LA point

O point: LA point (labial clinical crown midpoint)

contact points of left and right canines.

Posterior width: distance between central pits of left and right first molars.

Anterior length: vertical distance from left and right central incisors' mesial incisal edge to line joining distal contact points of left and right canines.

Posterior length: vertical distance from mesial incisal edge of left and right central incisors to line joining central pits of left and right first molars.

5) Alveolar arch width and length ${ }^{19)}$ (Fig. 6)

Anterior width: distance between deepest point of mucobuccal fold via distal contact points of left and right canines on a plane perpendicular to the occlusal plane.

Posterior width: distance between the deepest point of the mucobuccal fold via central pits of left and right first molars on a plane perpendicular to occlusal plane.

Anterior length: perpendicular distance parallel to occlusal plane joining distal contact points of left and right canines from most recessed point of mucobuccal fold of left central incisor root.

Posterior length: perpendicular distance parallel to occlusal plane joining central pits of left and right first molars from most recessed point of mucobuccal fold of left central incisor root.

As a control, the data reported by Tanoi $e t$ $a{ }^{26)}$ were used as the values of normal occlusion in 2) to 5).

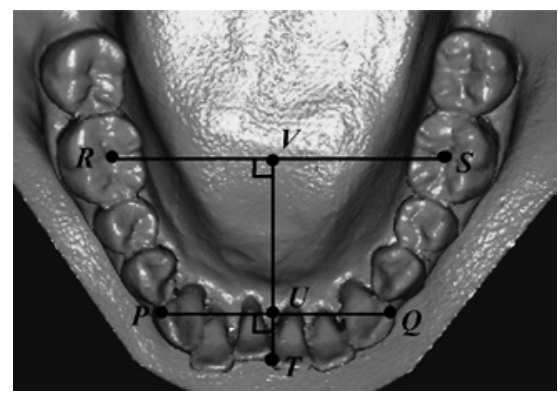

Fig. 5 Measurement method for dental arch width and length

PQ line: anterior width RS line: posterior width TU line: anterior length TV line: posterior length

\section{Statistical analysis}

1) Comparison of age-related change

The mean and standard deviation were calculated for each measurement. A paired $t$-test was used to compare the amount of change that occurred between the two age groups. A student's $t$-test was used to compare the crowding group with the normal group. The SPSS Statistics Version 19.0 software package was used in each of the tests, with the significance level set at $\mathrm{p}<0.05$.

2) Factors affecting age-related change

Multiple regression analysis was used to investigate factors affecting age-related change in maxillary and mandibular anterior tooth crowding. The amount of change in maxillary and mandibular anterior tooth crowding was set as the dependent variable, while the amount of crowding at each site, amount of change in the maxillary and mandibular dental arch and alveolar arch, and maxillary and mandibular anterior tooth angulation and inclination were set as independent variables. The regression equation was obtained using the stepwise method. The criteria for selection of independent variables were significance probabilities of $\mathrm{p}_{i n}=0.05$ and $\mathrm{p}_{\text {out }}=0.1$, and reference was made to the coefficient of determination $\left(R^{2}\right)$ as an indicator of the goodness of fit of the calculated regression. 


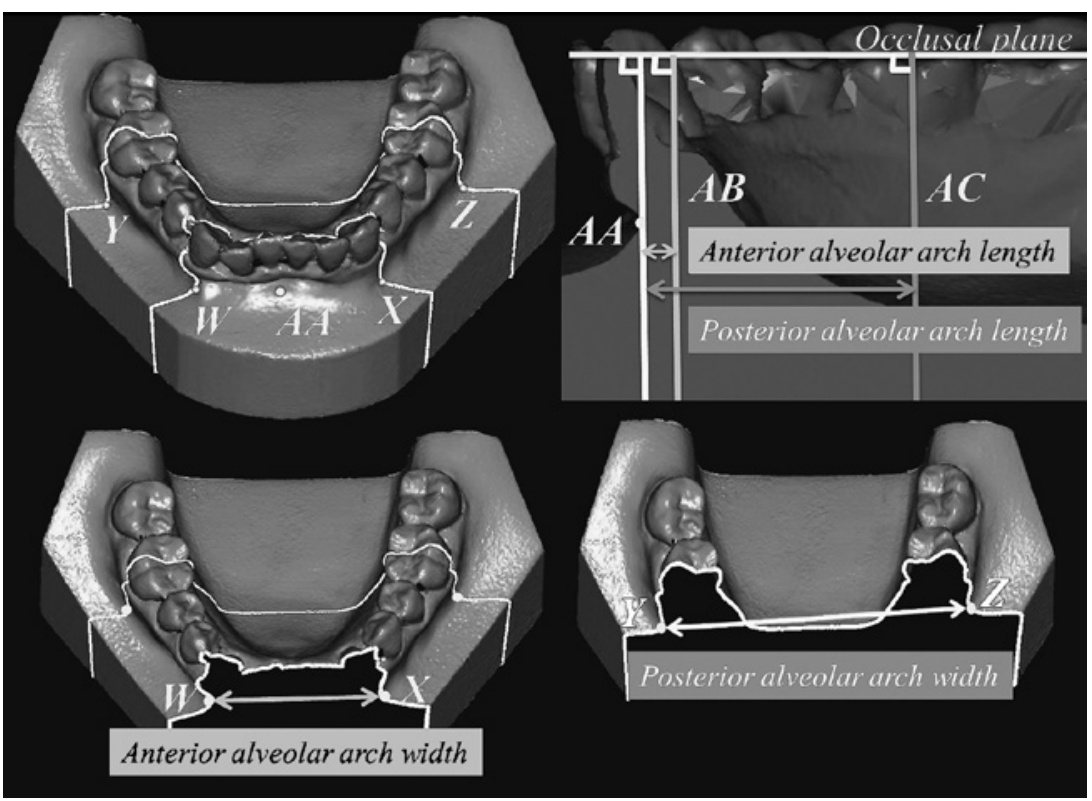

Fig. 6 Measurement method for alveolar arch width and length

WX line: anterior width

YZ line: posterior width

$\mathrm{AA}$ point to $\mathrm{AB}$ line: anterior length

AA point to AC line: posterior length

\section{Results}

\section{Measurement results}

Tables 1-5 show the mean values and standard deviation, age-related change, and paired $t$-test results for crowding, dental arch width and length, alveolar arch width and length, angulation, and inclination. Agerelated change and the results of the $t$-test in the Crowding group can be seen in $\mathrm{CT}_{1}-\mathrm{CT}_{2}$; while that in the Normal group can be seen in $\mathrm{NT}_{1}-\mathrm{NT}_{2}$. The results of the $t$-test on differences in age-related change between the Crowding and Normal groups are shown in D.

\section{1) Crowding (Table 1)}

In the maxilla, UT and U12 showed a significant increase in the Crowding and Normal groups. In the mandible, LT and L23 showed a significant increase in the Crowding and Normal groups. A significant increase was observed in L12 in the Crowding group only; a significant increase was also seen in L11 in the Normal group only.

An inter-group comparison revealed significant differences in the UT in the maxilla, and a greater increase was seen in the Crowding group than in the Normal group. Crowding increased in each group in the mandible, but there was no significant inter-group difference.

2) Angulation (Table 2)

In the maxilla, U3 showed a significant increase in the Crowding and Normal groups, with mesial inclination. In the mandible, L2 and L3 showed a significant increase in the Crowding and Normal groups, with mesial inclination. No significant differences were seen in the Normal group.

An inter-group comparison revealed no significant differences in the maxilla. In the mandible, only L3 showed a significant increase, and mesial inclination in the Crowding group was to a greater degree than that in the Normal group. 
Table 1 Change in amount of anterior crowding in young adulthood and middle age ( $\mathrm{mm}$ )

\begin{tabular}{|c|c|c|c|c|c|c|c|c|c|c|c|c|c|}
\hline \multirow{3}{*}{$\begin{array}{c}\text { Measure- } \\
\text { ment } \\
(\mathrm{mm})\end{array}$} & \multicolumn{6}{|c|}{ Crowding Group } & \multicolumn{7}{|c|}{ Normal Group } \\
\hline & \multicolumn{2}{|c|}{$20 \mathrm{~s}\left(\mathrm{CT}_{1}\right)$} & \multicolumn{2}{|c|}{$40 \mathrm{~s}\left(\mathrm{CT}_{2}\right)$} & \multicolumn{2}{|c|}{$\mathrm{CT}_{1}-\mathrm{CT}_{2}$} & \multicolumn{2}{|c|}{$20 \mathrm{~s}\left(\mathrm{NT}_{1}\right)$} & \multicolumn{2}{|c|}{$40 \mathrm{~s}\left(\mathrm{NT}_{2}\right)$} & \multicolumn{2}{|c|}{$\mathrm{NT}_{1}-\mathrm{NT}_{2}$} & \multirow{2}{*}{ D } \\
\hline & Mean & $\mathrm{SD}$ & Mean & $\mathrm{SD}$ & Mean & SD & Mean & $\mathrm{SD}$ & Mean & $\mathrm{SD}$ & Mean & $\mathrm{SD}$ & \\
\hline \multicolumn{14}{|l|}{ Maxillary } \\
\hline UT & 7.01 & 2.38 & 8.26 & 2.16 & $1.25 * *$ & 1.23 & 1.05 & 1.34 & 1.28 & 1.35 & $0.39 * *$ & 0.28 & $*$ \\
\hline U11 & 0.27 & 0.69 & 0.33 & 0.58 & 0.06 & 0.59 & 0.00 & 0.00 & 0.00 & 0.00 & 0.00 & 0.00 & NS \\
\hline U12 & 1.69 & 0.91 & 2.08 & 0.93 & $0.39 * *$ & 0.31 & 0.37 & 0.47 & 0.57 & 0.46 & $0.20 *$ & 0.20 & NS \\
\hline $\mathrm{U} 23$ & 1.68 & 0.68 & 1.88 & 0.52 & 0.20 & 0.44 & 0.16 & 0.24 & 0.15 & 0.23 & 0.00 & 0.07 & NS \\
\hline \multicolumn{14}{|c|}{ Mandibular } \\
\hline $\mathrm{LT}$ & 7.75 & 3.46 & 9.23 & 3.92 & $1.47 * *$ & 1.30 & 4.67 & 1.55 & 5.95 & 1.84 & $1.28 * *$ & 0.95 & NS \\
\hline L11 & 1.03 & 0.96 & 1.14 & 0.97 & 0.12 & 0.34 & 0.87 & 0.73 & 1.27 & 0.90 & $0.40 *$ & 0.56 & NS \\
\hline L12 & 1.45 & 0.81 & 1.87 & 0.96 & $0.30^{*}$ & 0.54 & 1.10 & 0.41 & 1.35 & 0.36 & 0.25 & 0.42 & NS \\
\hline L23 & 1.91 & 1.19 & 2.29 & 1.11 & $0.38^{* * *}$ & 0.33 & 0.79 & 0.74 & 0.98 & 0.71 & $0.19 *$ & 0.23 & NS \\
\hline
\end{tabular}

NS: not significant, $* \mathrm{p}<0.05, * * \mathrm{p}<0.01$

Table 2 Change in angulation in young adulthood and middle age $\left({ }^{\circ}\right)$

\begin{tabular}{|c|c|c|c|c|c|c|c|c|c|c|c|c|c|}
\hline \multirow{3}{*}{$\begin{array}{l}\text { Measure- } \\
\text { ment } \\
(\mathrm{mm})\end{array}$} & \multicolumn{6}{|c|}{ Crowding Group } & \multicolumn{7}{|c|}{ Normal Group } \\
\hline & \multicolumn{2}{|c|}{$20 \mathrm{~s}\left(\mathrm{CT}_{1}\right)$} & \multicolumn{2}{|c|}{$40 \mathrm{~s}\left(\mathrm{CT}_{2}\right)$} & \multicolumn{2}{|c|}{$\mathrm{CT}_{1}-\mathrm{CT}_{2}$} & \multicolumn{2}{|c|}{$20 \mathrm{~s}\left(\mathrm{NT}_{1}\right)$} & \multicolumn{2}{|c|}{$40 \mathrm{~s}\left(\mathrm{NT}_{2}\right)$} & \multicolumn{2}{|c|}{$\mathrm{NT}_{1}-\mathrm{NT}_{2}$} & \multirow{2}{*}{$\mathrm{D}$} \\
\hline & Mean & $\mathrm{SD}$ & Mean & $\mathrm{SD}$ & Mean & $\mathrm{SD}$ & Mean & $\mathrm{SD}$ & Mean & SD & Mean & $\mathrm{SD}$ & \\
\hline \multicolumn{14}{|l|}{ Maxillary } \\
\hline U1 & 0.84 & 4.60 & 0.89 & 4.60 & 0.05 & 1.68 & 2.93 & 2.76 & 3.27 & 3.05 & -0.38 & 0.71 & NS \\
\hline U2 & 1.54 & 4.46 & 1.64 & 5.13 & 0.09 & 2.09 & 4.69 & 3.26 & 3.95 & 4.33 & -0.19 & 1.31 & NS \\
\hline U3 & 4.24 & 5.00 & 7.21 & 3.47 & $2.97 * *$ & 2.37 & 4.33 & 2.53 & 6.44 & 3.49 & $2.67 *$ & 0.44 & NS \\
\hline \multicolumn{14}{|c|}{ Mandibular } \\
\hline L1 & -0.21 & 5.66 & -0.99 & 7.59 & -0.78 & 2.67 & 4.67 & 1.55 & 5.95 & 1.84 & -0.89 & 0.86 & NS \\
\hline L2 & -2.07 & 6.00 & -0.41 & 7.19 & $1.66^{*}$ & 2.34 & 0.87 & 0.73 & 1.27 & 0.90 & 0.44 & 1.21 & NS \\
\hline L3 & 2.30 & 4.45 & 3.65 & 4.06 & $1.35^{*}$ & 1.75 & 1.10 & 0.41 & 1.35 & 0.36 & 0.11 & 0.53 & $*$ \\
\hline
\end{tabular}

NS: not significant, $* \mathrm{p}<0.05, * * \mathrm{p}<0.01$

Angle formed by tooth crown axis and line orthogonal to occlusal plane was calculated. Mesial inclination of crown with respect to occlusal plane is indicated as positive $(+)$ and distal inclination as negative $(-)$.

3) Inclination (Table 3)

In the maxilla, no significant differences were seen in U1 in the Crowding group. A significant decrease was observed in U2, with lingual inclination. A significant increase was observed in U3, with labial inclination. In the Normal group, U1 and U2 showed a significant increase, with labial inclination. A significant decrease was observed in U3, with lingual inclination. In the mandible, no significant differences were seen in L1 or L2. A significant decrease was seen in L3, with lingual inclination. In the Normal group, L1, L2, and L3 showed a significant decrease, with lingual inclination.

An inter-group comparison revealed significant differences in U2 and U3 in the maxilla. In U2, the Crowding group showed 
Table 3 Change in inclination in young adulthood and middle age $\left({ }^{\circ}\right)$

\begin{tabular}{|c|c|c|c|c|c|c|c|c|c|c|c|c|c|}
\hline \multirow{3}{*}{$\begin{array}{c}\text { Measure- } \\
\text { ment } \\
(\mathrm{mm})\end{array}$} & \multicolumn{6}{|c|}{ Crowding Group } & \multicolumn{7}{|c|}{ Normal Group } \\
\hline & \multicolumn{2}{|c|}{$20 \mathrm{~s}\left(\mathrm{CT}_{1}\right)$} & \multicolumn{2}{|c|}{$40 \mathrm{~s}\left(\mathrm{CT}_{2}\right)$} & \multicolumn{2}{|c|}{$\mathrm{CT}_{1}-\mathrm{CT}_{2}$} & \multicolumn{2}{|c|}{$20 \mathrm{~s}\left(\mathrm{NT}_{1}\right)$} & \multicolumn{2}{|c|}{$40 \mathrm{~s}\left(\mathrm{NT}_{2}\right)$} & \multicolumn{2}{|c|}{$\mathrm{NT}_{1}-\mathrm{NT}_{2}$} & \multirow{2}{*}{$\mathrm{D}$} \\
\hline & Mean & SD & Mean & $\mathrm{SD}$ & Mean & SD & Mean & $\mathrm{SD}$ & Mean & $\mathrm{SD}$ & Mean & SD & \\
\hline \multicolumn{14}{|l|}{ Maxillary } \\
\hline $\mathrm{U} 1$ & 7.64 & 6.61 & 8.86 & 6.76 & 1.22 & 2.74 & 9.98 & 4.39 & 10.81 & 4.85 & $1.04 *$ & 0.45 & NS \\
\hline U2 & 6.74 & 3.32 & 4.99 & 4.15 & $-1.76^{*}$ & 2.09 & 9.36 & 4.07 & 10.11 & 4.18 & $1.17 *$ & 0.66 & $* *$ \\
\hline U3 & -6.81 & 5.70 & -4.97 & 6.52 & $1.84 * *$ & 1.91 & -2.42 & 4.84 & -4.65 & 4.67 & $-23.1^{*}$ & 0.49 & $* *$ \\
\hline \multicolumn{14}{|c|}{ Mandibular } \\
\hline L1 & 2.33 & 7.27 & 2.13 & 7.15 & -0.20 & 2.85 & 4.95 & 4.91 & 3.24 & 4.93 & $-1.92 *$ & 0.43 & NS \\
\hline L2 & -2.29 & 8.08 & -1.73 & 9.47 & 0.56 & 3.41 & 3.92 & 5.05 & 2.83 & 2.83 & $-1.98^{*}$ & 0.80 & $*$ \\
\hline L3 & -4.28 & 7.39 & -6.98 & 7.02 & $-2.70 * *$ & 2.39 & -3.63 & 4.23 & -6.51 & 3.71 & $-2.37 *$ & 0.44 & NS \\
\hline
\end{tabular}

NS: not significant, $* \mathrm{p}<0.05, * * \mathrm{p}<0.01$

Labiobuccal inclination of crown with respect to occlusal plane is indicated as positive $(+)$ and lingual inclination as negative $(-)$.

Table 4 Change in dental arch in young adulthood and middle age $(\mathrm{mm})$

\begin{tabular}{|c|c|c|c|c|c|c|c|c|c|c|c|c|c|}
\hline \multirow{3}{*}{$\begin{array}{l}\text { Measure- } \\
\text { ment } \\
(\mathrm{mm})\end{array}$} & \multicolumn{6}{|c|}{ Crowding Group } & \multicolumn{7}{|c|}{ Normal Group } \\
\hline & \multicolumn{2}{|c|}{$20 \mathrm{~s}\left(\mathrm{CT}_{1}\right)$} & \multicolumn{2}{|c|}{$40 \mathrm{~s}\left(\mathrm{CT}_{2}\right)$} & \multicolumn{2}{|c|}{$\mathrm{CT}_{1}-\mathrm{CT}_{2}$} & \multicolumn{2}{|c|}{$20 \mathrm{~s}\left(\mathrm{NT}_{1}\right)$} & \multicolumn{2}{|c|}{$40 \mathrm{~s}\left(\mathrm{NT}_{2}\right)$} & \multicolumn{2}{|c|}{$\mathrm{NT}_{1}-\mathrm{NT}_{2}$} & \multirow{2}{*}{$\mathrm{D}$} \\
\hline & Mean & $\mathrm{SD}$ & Mean & SD & Mean & SD & Mean & $\mathrm{SD}$ & Mean & $\mathrm{SD}$ & Mean & SD & \\
\hline \multicolumn{14}{|l|}{ Maxillary } \\
\hline A. width & 39.60 & 2.04 & 40.03 & 2.29 & $0.44 *$ & 0.55 & 39.89 & 2.39 & 39.35 & 2.38 & $-0.67 *$ & 0.39 & $* *$ \\
\hline P. width & 50.05 & 4.63 & 50.56 & 4.78 & $0.50 *$ & 0.65 & 50.67 & 2.96 & 50.02 & 2.79 & $-0.30 *$ & 0.14 & $* *$ \\
\hline A. length & 13.30 & 1.80 & 12.94 & 2.01 & $-0.35^{* *}$ & 0.34 & 13.47 & 2.12 & 14.23 & 2.84 & $0.38 *$ & 0.34 & $* *$ \\
\hline P. length & 32.90 & 2.50 & 32.71 & 2.68 & -0.19 & 0.47 & 33.06 & 3.14 & 32.85 & 3.72 & 0.18 & 0.23 & $*$ \\
\hline \multicolumn{14}{|l|}{ Mandibular } \\
\hline A. width & 31.46 & 1.72 & 30.70 & 1.76 & $-0.75^{* *}$ & 0.48 & 32.17 & 1.35 & 31.34 & 1.50 & $-1.05^{*}$ & 0.61 & NS \\
\hline P. width & 43.34 & 5.59 & 43.86 & 5.41 & $0.52 * *$ & 0.38 & 43.87 & 1.99 & 43.38 & 1.84 & $-0.44^{*}$ & 0.22 & $* *$ \\
\hline A. length & 7.83 & 1.08 & 7.80 & 1.33 & -0.03 & 0.62 & 8.65 & 0.77 & 7.62 & 1.10 & $-0.71 * *$ & 0.48 & $*$ \\
\hline P. length & 28.29 & 1.61 & 27.90 & 1.73 & $-0.38 *$ & 0.58 & 28.50 & 1.66 & 27.01 & 2.13 & $-1.12^{* * *}$ & 0.70 & $*$ \\
\hline
\end{tabular}

NS: not significant, ${ }^{*} \mathrm{p}<0.05, * * \mathrm{p}<0.01$

greater lingual inclination the Normal group. In U3, the Crowding group showed greater labial inclination than the Normal group. Significant differences were observed in L2 in the mandible. The Normal group showed greater lingual inclination than the Crowding group.

4) Dental arch width and length (Table 4)

In the maxilla in the Crowding group, anterior and posterior width showed a significant increase, while anterior length showed a significant decrease. In the Normal group, the opposite was seen. Anterior and posterior width showed a significant decrease, while anterior length showed a significant increase. In the mandible in the Crowding group, anterior width showed a significant decrease, while posterior width showed a significant increase and posterior length a significant decrease. 
Table 5 Change in alveolar arch in young adulthood and middle age $(\mathrm{mm})$

\begin{tabular}{|c|c|c|c|c|c|c|c|c|c|c|c|c|c|}
\hline \multirow{3}{*}{$\begin{array}{l}\text { Measure- } \\
\text { ment } \\
(\mathrm{mm})\end{array}$} & \multicolumn{6}{|c|}{ Crowding Group } & \multicolumn{7}{|c|}{ Normal Group } \\
\hline & \multicolumn{2}{|c|}{$20 \mathrm{~s}\left(\mathrm{CT}_{1}\right)$} & \multicolumn{2}{|c|}{$40 \mathrm{~s}\left(\mathrm{CT}_{2}\right)$} & \multicolumn{2}{|c|}{$\mathrm{CT}_{1}-\mathrm{CT}_{2}$} & \multicolumn{2}{|c|}{ 20s $\left(\mathrm{NT}_{1}\right)$} & \multicolumn{2}{|c|}{$40 \mathrm{~s}\left(\mathrm{NT}_{2}\right)$} & \multicolumn{2}{|c|}{$\mathrm{NT}_{1}-\mathrm{NT}_{2}$} & \multirow{2}{*}{ D } \\
\hline & Mean & SD & Mean & $\mathrm{SD}$ & Mean & SD & Mean & SD & Mean & $\mathrm{SD}$ & Mean & $\mathrm{SD}$ & \\
\hline \multicolumn{14}{|l|}{ Maxillary } \\
\hline A. width & 38.65 & 2.07 & 39.57 & 2.38 & $0.93^{*}$ & 1.32 & 42.02 & 2.58 & 41.51 & 2.22 & $-0.50 *$ & 0.26 & $* *$ \\
\hline P. width & 64.46 & 3.83 & 64.93 & 3.54 & $0.48 *$ & 0.69 & 62.96 & 6.47 & 62.66 & 6.16 & $-0.24 *$ & 0.12 & $* *$ \\
\hline A. length & 8.27 & 1.32 & 7.56 & 1.42 & $-0.71 *$ & 1.04 & 7.90 & 1.39 & 7.63 & 2.00 & -0.06 & 0.80 & NS \\
\hline P. length & 28.83 & 1.41 & 28.04 & 1.84 & $-0.80^{*}$ & 1.06 & 26.23 & 0.98 & 25.88 & 1.53 & -0.41 & 0.65 & NS \\
\hline \multicolumn{14}{|l|}{ Mandibular } \\
\hline A. width & 30.85 & 2.28 & 29.66 & 1.95 & $-1.19 * *$ & 1.03 & 34.01 & 1.50 & 33.42 & 2.41 & $-0.82^{*}$ & 0.90 & NS \\
\hline P. width & 59.46 & 4.09 & 59.97 & 4.46 & $0.51^{*}$ & 0.73 & 57.30 & 6.04 & 56.62 & 6.11 & $-0.84^{*}$ & 0.77 & $* *$ \\
\hline A. length & 4.53 & 1.26 & 3.54 & 1.35 & $-0.98^{*}$ & 1.08 & 7.46 & 1.32 & 6.75 & 0.76 & $-0.56^{*}$ & 0.54 & NS \\
\hline P. length & 25.36 & 1.39 & 24.16 & 1.85 & $-1.20 *$ & 1.31 & 24.64 & 4.11 & 23.43 & 3.67 & $-1.02^{*}$ & 0.60 & NS \\
\hline
\end{tabular}

NS: not significant, $* \mathrm{p}<0.05, * * \mathrm{p}<0.01$

An inter-group comparison revealed significant differences in anterior width, posterior width, anterior length, and posterior length in the maxilla. The Crowding group showed a greater increase in anterior and posterior width than the Normal group. The Crowding group showed a greater decrease in anterior length and posterior length than the Normal group. In the mandible, significant differences were seen in posterior width, anterior length, and posterior length. The Crowding group showed a greater increase in anterior width than the Normal group. The Normal group showed a greater decrease in anterior length and posterior length than the Crowding group.

5) Alveolar arch width and length (Table 5)

Both the maxillary and mandibular alveolar arch width and length showed similar results to those for the dental arch. In the Crowding group, anterior width and posterior width showed a significant increase, while anterior length and posterior length showed a significant decrease in the maxilla. Meanwhile, in the Normal group, anterior width and posterior width showed a significant decrease. In the mandible, in the Crowding group, anterior width showed a significant decrease, while posterior width showed a sig- nificant increase, and anterior and posterior length a significant decrease.

An inter-group comparison revealed significant differences in anterior and posterior width in the maxilla. The Crowding group showed a greater increase in anterior and posterior width than the Normal group; it also showed a greater decrease in anterior and posterior length. In the mandible, significant differences were seen in posterior width. The Crowding group showed a greater increase in posterior width than the Normal group.

\section{Factors affecting age-related change}

The results of stepwise multiple regression analysis are shown in Tables 6 and 7. Table 6 shows the results of multiple regression analysis with UT as a dependent variable. Table 7 shows the results of multiple regression analysis with LT as a dependent variable. The results of an analysis of variance (ANOVA) were significant, with $R^{2}$ values of 0.370 and 0.991; thus, the goodness of fit was assessed to be high. There was no problem with the Durbin-Watson ratios, which were 1.813 and 2.183 , respectively. There were no outliers in which predicted values exceeded $\pm 3 \mathrm{SD}$ with respect to the measured values. In the results of an analysis with UT as the dependent vari- 
Table 6 Multiple regression analysis with maxillary irregularity index as dependent variable

\begin{tabular}{cccccc}
\hline \hline Independent variable & $\begin{array}{c}\text { Partial } \\
\text { regression } \\
\text { coefficient }\end{array}$ & $\begin{array}{c}\text { Standard } \\
\text { partial } \\
\text { regression } \\
\text { coefficient }\end{array}$ & $\begin{array}{c}\text { Significance } \\
\text { probability } \\
(\mathrm{p})\end{array}$ & $\begin{array}{c}\text { Lower } \\
\text { limit }\end{array}$ & $\begin{array}{c}\text { Upper } \\
\text { limit }\end{array}$ \\
\hline Upper posterior alveolar arch length & -0.609 & -0.609 & 0.036 & -1.362 & -0.058 \\
\hline
\end{tabular}

$\mathrm{R}^{2}=0.370$, ANOVA $\mathrm{p}<0.05, \mathrm{n}=12$

Table 7 Multiple regression analysis with mandibular irregularity index as dependent variable

\begin{tabular}{|c|c|c|c|c|c|}
\hline \multirow[b]{2}{*}{ Independent variable } & \multirow{2}{*}{$\begin{array}{l}\text { Partial } \\
\text { regression } \\
\text { coefficient }\end{array}$} & \multirow{2}{*}{$\begin{array}{l}\text { Standard } \\
\text { partial } \\
\text { regression } \\
\text { coefficient }\end{array}$} & \multirow{2}{*}{$\begin{array}{c}\text { Significance } \\
\text { probability } \\
\text { (p) }\end{array}$} & \multicolumn{2}{|c|}{$95 \%$ confidence interval } \\
\hline & & & & $\begin{array}{l}\text { Lower } \\
\text { limit }\end{array}$ & $\begin{array}{c}\text { Upper } \\
\text { limit }\end{array}$ \\
\hline L12 & 0.990 & 0.744 & 0 & 1.552 & 2.005 \\
\hline L23 & 0.965 & 0.368 & 0 & 1.090 & 1.785 \\
\hline Lower anterior alveolar arch width & -0.900 & -0.203 & 0.001 & -0.367 & -0.145 \\
\hline Lower canine inclination & 0.722 & 0.111 & 0.028 & 0.009 & 0.112 \\
\hline
\end{tabular}

$\mathrm{R}^{2}=0.991$, ANOVA $\mathrm{p}<0.001$

able, a decrease in maxillary posterior alveolar arch length was extracted. An analysis with LT as the dependent variable identified increases in L12 and L23; a decrease in mandibular anterior alveolar arch width; and lingual inclination in L3. The increase in L12 had a particularly strong association.

\section{Discussion}

\section{Study purpose}

Many studies have investigated age-related change in normal occlusion and during the post-retention phase of orthodontic treatment $^{3-6,10,11,15,17,23,26,28)}$. To our knowledge, however, no studies to date have investigated longterm change in patients with malocclusion who have not undergone orthodontic treatment. Many long-term reports covering follow-up periods of 10 years or more have described such change in patients aged in their 20 s to $40 \mathrm{~s}^{2,15,26)}$. One study noted that agerelated change in the dentition was more likely to occur during the third decade of $\operatorname{life}^{5)}$. The present study investigated age- related change in individuals with untreated Angle Class I crowding between when the same subject was in their twenties and about two decades later, going on to compare this with that in individuals with normal occlusion as a control.

\section{Study materials}

Dental plaster casts were obtained from the 1990-1991 graduates of Tokyo Dental College. This group was selected for potential enrolment due to ease of access (their casts were already in long-term storage at this college and known to be well preserved) as a cohort with no history of orthodontic treatment. No X-ray evidence had been kept on record, however, and none could be obtained now that they were in their 40 s due to ethical considerations. The presence or absence of third molars was not taken into consideration as only dental plaster casts were to be used. Obtaining current plaster casts for a comparison was more difficult: consent had to be obtained; many now had prosthetic crowns; and those who had subsequently undergone orthodontic treatment were ineligible under 
the study protocol. Consequently, materials for inclusion in the study could only be obtained from 12 people comprising 10 men and 2 women. With respect to the male-female ratio, this was a population with a large number of men to start with, as it comprised solely graduates of a dental college. In addition, there has been an increase in women undergoing orthodontic treatment in the past 20 years, which inevitably decreased the pool of suitable materials that could be obtained from women under the exclusion criteria. The same can also be said of the study by Tanoi $e t a l^{26)}$, who used the same population, but selecting only those with normal occlusion. One purpose of the present study was to compare age-related change in malocclusion with that in normal occlusion. Therefore, since the male-female ratio was about the same as in that in the Tanoi study, dental casts from their cohort of 12 individuals were used where they met the same age conditions as those of the present study.

\section{Measurement method}

A 3-D laser scanner was used to measure the shape of the dental casts, as in the study by Tanoi et $a l^{26)}$. According to another earlier study, the dental cast measurement precision of the 3-D laser scanner used in the present study is $0.07 \pm 0.07 \mathrm{~mm}$ on the $\mathrm{X}$-axis, $0.07 \pm$ $0.06 \mathrm{~mm}$ on the Y-axis, and $0.05 \pm 0.05 \mathrm{~mm}$ on the Z-axis ${ }^{16}$. Based on this finding, it is believed that this device offered a level of precision sufficient for the purposes of this study. Therefore, objective, reproducible crown measurements could be obtained using the 3-D universal measuring machine. Dental cast images were then reproduced on a computer using a high power field (HPF) to eliminate the possibility of human error.

\section{Results of crowding}

All previously reported investigations on anterior crowding in the maxilla and mandible describe an increase with age $\mathrm{ag}^{2-6,10,11,15,17,23,26,28)}$. In particular, many studies have reported an increase in mandibular anterior crowding $^{2-6,10,11,15,17,23,26,28)}$, indicating that this is a char- acteristic change with age. The results of the present study revealed that maxillary and mandibular crowding increased over time. The amount of crowding by site was investigated. In the maxillary teeth, the amount of crowding between the central incisors increased in both the Crowding and Normal groups. In the mandibular teeth, the amount of crowding between the central incisors increased in the Crowding group, while the amount of crowding between the lateral incisors and canines increased in both groups. Crowding between the maxillary central incisors and between the mandibular lateral incisors and canines was thus more likely to increase, irrespective of whether a patient belonged to the Crowding or Normal group.

In the Crowding group, casts made when the subjects were in their 20s exhibited linguoversion of the maxillary lateral incisors and infralabioversion of the maxillary canines, with broken contact at these locations in many cases. This suggests that aging-associated crowding may further increase at locations where normal contact is lost, and that tooth inclination and rotation involved in the lingual inclination of the lateral incisors and the mesiolabial inclination of the canines may also lead to age-related crowding. The increased crowding between the mandibular central incisors and between the mandibular lateral incisors and canines seen in the Crowding group may be associated with tooth morphology. The maxillary central incisors in Japanese individuals are often shovelshaped $^{25)}$, and occlusion between the marginal crest and the mandibular lateral incisors results in linguoversion. Crowding may thus increase due to a range of factors, including lingual inclination of the maxillary lateral incisors and mandibular canines.

A comparison of the magnitude of agerelated change between the two groups showed that the difference in the amount of crowding was only significant for the maxillary teeth, with a larger increase in the Crowding group. This suggests that increased crowding of the maxillary teeth may be characteristic of age-related change in individuals 
with Angle Class I crowding. No significant differences were observed in age-related change in crowding of the mandibular teeth between the two groups. This suggests that crowding may increase by around the same amount with advancing age, whether malocclusion is present or not.

\section{Results of angulation/inclination}

Few studies have investigated angulation/ inclination. One earlier study reported that most of the maxillary teeth showed mesial inclination, and that this intensified with increasing age ${ }^{27)}$. Others have reported labial inclination of the maxillary front teeth ${ }^{12,15)}$. In the present study, mesiolabial inclination of the canines and lingual inclination of the central and lateral incisors was observed, but no significant change in the central incisors in the Crowding group. Meanwhile, in the Normal group, mesiolingual inclination of the canines and labial inclination of the central and lateral incisors was observed, with labiolingual inclination changing over time. The lips and tongue are believed to affect the inclination of the tooth axes of the front teeth $^{9,18,20,24,29)}$, and in the Crowding group, the contact relationship with neighboring surfaces had already been lost due to inclination or rotation, so its protective effect against lip pressure was inadequate. As a result, labial inclination of the central incisors is controlled while lingual inclination of the lateral incisors occurs, increasing the amount of crowding between the maxillary central incisors. Crowding of the space between the maxillary lateral incisors and canines may not have increased, despite the mesial inclination of the canines because labial inclination also occurred at the same time. In addition to angulation/inclination, rotation may also be a factor involved in increased crowding, and there is scope for further study on this subject. In the present study, lingual inclination of the mandibular central and lateral incisors and canines was observed in subjects with normal occlusion; in the Crowding group, however, mesial inclination of the lateral incisors and mesiolingual inclination of the canines was evident. Lingual inclination of the canines was common to both groups, and this has also been reported in an earlier study ${ }^{15)}$. In the present study, lingual inclination of the mandibular canines was an agerelated change that occurred irrespective of whether the patient belonged to the Crowding or Normal group, and this is a clinically noteworthy change.

\section{Results for width and length of dental and alveolar arches}

Age-related change in the width and length of the dental arch and alveolar arch differed between the two groups. In the Normal group, the width of the maxillary jaw showed a decrease and length an increase; whereas in the Crowding group width showed an increase and length a decrease. The magnitude of these age-related changes also differed between the two groups. This may also have been related to the inclination of the maxillary front teeth, with an increase in the anterior width and decrease in the anterior length of the maxillary jaw in the Crowding group due to mesiolabial inclination of the canines. The anterior width and posterior length of the mandible showed a decrease in both the Crowding and Normal groups. Other studies have reported that the width between the mandibular canines decreases over time, and that the length of the mandibular dental arch also decreases ${ }^{5,10,23,28}$. The present results support these earlier findings. One study on long-term post-retention stability reported that the width between the mandibular canines showed a decrease after orthodontic treatment, irrespective of whether this had included expansion ${ }^{14)}$. This decrease in the anterior width of the mandibular jaw may be due to lingual inclination of the canines, which may contribute to increased crowding.

\section{Results of factors affecting age-related change}

In a multiple regression analysis, a significant correlation was found between an increase in mandibular anterior crowding 
and lingual inclination of the mandibular anterior $\operatorname{teeth}^{26)}$. In the present study, an increase in maxillary crowding in the Crowding group was associated with maxillary posterior alveolar arch length, and an increase in mandibular crowding was associated with L12, L23, mandibular anterior alveolar arch width, and mandibular canine inclination. Associations were therefore identified between a decrease in maxillary posterior alveolar arch length, a decrease in mandibular anterior alveolar arch width, or labial inclination of the mandibular canines and an increase in crowding. Change in the mandibular lateral incisors and canines had a particularly large effect.

\section{Conclusion}

Oral plaster casts obtained from the same orthodontic patients with untreated Angle Class I crowding over the 20-year period from their twenties to their forties were compared in order to investigate age-related change in dentition.

Age-related change in anterior crowding in patients with untreated Angle Class I crowding comprised an increase in maxillary crowding due to a decrease in maxillary arch length. The results suggest that lingual inclination of the maxillary lateral incisors and mesiolingual inclination of the maxillary canines is also involved. Crowding showed an increase due to a decrease in the anterior arch width and lingual inclination of the canines in the mandible. An increase was observed in broken contact between the mandibular central incisors and between the lateral incisors and the canines, in particular, which may have been due to age-related inclination of the mandibular lateral incisors and canines. A comparison between subjects with Angle Class I crowding and those with normal occlusion revealed that age-related change in the dentition would occur 20 years later, irrespective of the amount of crowding in the third decade of life. By the time the subjects were in their forties, the amount of mandibular anterior crowding had increased by around the same mount, but the increase in maxillary anterior crowding was greater in those with Angle Class I crowding.

\section{Acknowledgements}

We wish to express our gratitude to $\mathrm{Mr}$. Shigeru Okano, Tokyo Dental College Oral Health Science Center. We are also grateful to the professors of our school's Department of Orthodontics for their advice and guidance throughout this process.

\section{References}

1) Andrews LF (1972) The six keys to normal occlusion. Am J Orthod 62:296-309.

2) Bishara SE, Treder Jean E, Jakobsen JR (1994) Facial and dental changes in adulthood. Am J Orthod Dentofacial Orthop 106:175-186.

3) Blake M, Garvey MT (1998) Rationale for retention following orthodontic treatment. J Can Dent Assoc 64:640-643.

4) Carter GA, McNamara Jr JA (1998) Longitudinal dental arch changes in adults. Am J Orthod Dentofacial Orthop 114:88-99.

5) Dager MM, McNamara JA, Baccetti T, Franchi L (2008) Aging in the craniofacial complex. Angle Orthod 78:440-444.

6) Durbin DD (2001) Relaps and the need for permanent fixed retention. J Clin Orthod 35: 723-727.

7) Fukagawa H, Motegi E, Fuma A, Nomura M, Kano M, Sueishi K, Okano S (2010) Tooth inclination in elderly with many remaining teeth observed by 3-D imaging. Bull Tokyo Dent Coll 51:69-76.

8) Fuma A, Motegi E, Fukagawa H, Nomura M, Kano M, Sueishi K, Okano S (2010) Mesiodistal tooth angulation in elderly with many remaining teeth observed by 3-D imaging. Bull Tokyo Dent Coll 51:57-64.

9) Harvold EP (1968) The role of function in the etiology and treatment of malocclusion. Am J Orthod 54:883-898.

10) Henrikson J, Persson M, Thilander B (2001) Long-term stability of dental arch form in normal occlusion from 13 to 31 years of age. Eur J Orthod 23:51-61.

11) Kahl-Nieke B (1996) Retention and stability consideration for adult patients. Dent Clin 
North Am 40:961-994.

12) Kumakiri K (1969) A study on the contact facets of the neighbouring posterior teeth of human dentition. J Jpn Prosthodont Soc 13: $1-38$.

13) Little RM (1975) The irregularity index: A quantitative score of mandibular anterior alignment. Am J Orthod 68:554-563.

14) Little RM (1999) Stability and relapse of mandibular anterior alignment: University of Washington studies. Semin Orthod 5:191204.

15) Mishima H (1985) A longitudinal observations on the dental arch, vertical dimension, overlap of anterior teeth, and occlusal factors in the same persons from the point of aging. Shikwa Gakuho 8:1143-1167. (in Japanese)

16) Motohashi N, Nunota A, Kuroda T (1997) Study on CAM system for dental model. J Stomatol Soc 64:427-435.

17) Myser SA, Campbell PM, Boley J, Buschang PH (2013) Long-term stability: Postretention changes of the mandibular anterior teeth. Am J Orthod Dentofacial Orthop 144:420-429.

18) Nezu H (1973) A study of oral muscle pressures exerted on the upper and lower incisor teeth by the lips and tongue in subjects with normal occlusion and malocclusion. Shikwa Gakuho 73:749-787. (in Japanese)

19) Nomura M, Kano M, Motegi E, Fuma A, Mizuno H, Okano S, Sueishi K (2013) Model analysis in "8020" achievers using threedimensional images. Bull Tokyo Dent Coll 54: 223-232.

20) Proffit WR (1978) Equilibrium theory revisited. Angle Orthod 48:175-186.

21) Ricketts RM (1978) A detailed consideration of the line of occlusion. Angle Orthod 48: 274-282.

22) Roth RH (1981) Functional occlusion for the orthodontist. J Clin Orthod 15:32-51,100-123,
174-198, 246-265.

23) Sinclair PM, Little RM (1983) Maturation of untreated normal occlusions. Am J Orthod 83: 114-123.

24) Takehana Y, Masuda Y, Kageyama T, Okazaki R, Murakami M, Yamada K (2017) The relationship between lip-closing force and dental arch morphology in patient with Angle Class I malocclusion. J Oral Rehabil 44:205-212.

25) Tanaka N, Goto M (2014) Morphological studies on the dentitions of extant Japanese females. J Tsurumi University 51:87-102. (in Japanese)

26) Tanoi A, Motegi E, Sueishi K (2012) Change in dentition over 20 years from third decade of life. Orthod Waves 71:90-98.

27) Trauner F (1912) The causes of progressive movement of the teeth toward the front. Am J Orthod 3:144-158.

28) Tsiopas N, Nilner M, Bondemark L, Bjerklin K (2011) A 40 years follow-up of dental arch dimensions and incisor irregularity in adults. Eur J Orthod 35:230-235.

29) Urs T, Benqt I (1986) Pressure from the lips on the teeth and malocclusion. Am J Orthod 90:234-242.

30) Watanabe A, Mohri T, Watanabe N, Watanabe Y, Miyazaki H, Saito I (2009) Epidemiological investigation of malocclusion in Japan using the Index of Orthodontic Treatment Need (IOTN). Orthod Waves-Jpn Ed 68:142-154. (in Japanese)

Correspondence:

Dr. Yuka Saito

Department of Orthodontics,

Tokyo Dental College,

1-2-2 Masago, Mihama-ku,

Chiba 261-8502, Japan

E-mail: saitouyuka@tdc.jp 